\title{
A pluriatividade das famílias rurais no Nordeste e no Sul do Brasil: pobreza rural e políticas públicas ${ }^{1}$
}

\author{
Carlos Alves do Nascimento ${ }^{2}$
}

\section{Resumo}

$\mathrm{O}$ artigo desfaz a ideia de que as famílias rurais pluriativas encontram ambientes favoráveis ao seu crescimento em regiões com economias locais mais dinâmicas e modernas. A pesquisa está apoiada em informações processadas a partir dos microdados da Pesquisa Nacional por Amostra de Domicílios - PNAD (1992 a 1999 e 2001 a 2005). Defende-se que, no caso da Região Sul, o crescimento (ou o não crescimento) da pluriatividade - e sua influência sobre o conjunto da agricultura familiar - depende fundamentalmente de concepções e ações políticas (políticas públicas). No Nordeste, a pluriatividade cresce associada à pobreza no interior da região.

Palavras-chave: Pluriatividade agrícola; Pobreza rural; Políticas públicas; Famílias rurais.

\begin{abstract}
The pluriactivity of rural households in the Brazilian Northeast and South: rural poverty and public policies

The paper aims to undo the idea that pluriactivity finds favorable environment to its growth in regions with dynamic and modern local economies. The research is based on information processing from the microdata of the Pesquisa Nacional por Amostra de Domicílios - PNAD (from 1992 to 1999 and from 2001 to 2005). This paper also points out that, in the case of the South region, the growth (or not growth) of pluriactivity - and its influence over family farms - depends fundamentally on political conceptions and political actions. In the Northeast, pluriactivity increases associated to poverty in interior areas of the region.
\end{abstract}

Key words: Pluriactivity; Rural poverty; Public policies; Family farm. JEL Q18, Q19, R23.

Se nós, economistas, prestássemos menos atenção aos nossos próprios desejos e mais aos fatos, imediatamente surgiriam dúvidas quanto às virtudes realistas de uma teoria que nos levasse a esperar um resultado muito diferente (Joseph A. Schumpeter).

\section{Introdução}

A epígrafe acima sintetiza muito bem a ideia básica do presente artigo. $\mathrm{Ou}$ seja, aborda-se aqui uma temática não a partir de concepções teóricas ${ }^{3}$ que,

(1) Trabalho recebido em agosto de 2007 e aprovado em maio de 2008. O autor agradece a valiosa contribuição do parecerista para uma melhor apresentação das idéias defendidas no artigo.

(2) Professor da Universidade Federal de Uberlândia (UFU), Uberlândia, MG, Brasil. E-mail: $\underline{\text { can@ie.ufu.br. }}$

(3) Ver, especialmente, Schneider (2003) e Kageyama (1998). 
conforme pretendemos mostrar, não encontram respaldo empírico na realidade brasileira concreta. Trata-se de uma temática que - como tantas outras - foi importada de realidades estranhas à brasileira, especialmente da Europa, sem a devida consideração das especificidades brasileiras. Está se falando da pluriatividade das famílias rurais; ou seja, de famílias rurais que conciliam entre seus membros atividades agrícolas e não agrícolas no interior ou fora do estabelecimento rural.

A importância da pluriatividade como um instrumento alternativo para o êxodo rural gerado pelas transformações capitalistas no campo, especialmente a partir dos anos 70, tem sido reconhecida de forma crescente não apenas entre acadêmicos, mas também pelas autoridades políticas e econômicas da União Européia (UE), em virtude da sua histórica preocupação em preservar a sua estrutura agrária baseada na agricultura familiar e em evitar mais problemas populacionais nas áreas urbanas (Hill, 1984; Fuller, 1990; Tolosana; Persiva, 1992).

No Brasil, a pluriatividade só tem encontrado relativa importância entre alguns pesquisadores acadêmicos que se interessam pelo tema - cuja origem remonta aos estudos dos part-time farmers, no contexto da modernização da agricultura na UE, e da especialização produtiva do trabalho, que depois evoluíram para a noção de pluriatividade (Kageyama, 1998; Graziano da Silva, 1999; Schneider, 2003; Sacco dos Anjos, 2003; Nascimento, 2005a).

Não obstante essa discussão seja ainda muito recente no Brasil, o referido debate já começou, muito recentemente, a encontrar espaço em certas instituições públicas oficiais do país. Exemplo disso foi a realização pelo Ministério do Desenvolvimento Agrário (MDA) junto com o Conselho Nacional de Desenvolvimento Rural Sustentável (Condraf), do Seminário Nacional de Desenvolvimento Rural Sustentável, em Brasília, nos dias 23 a 25 de agosto de 2005, que teve como um dos painéis principais "O papel da pluriatividade numa estratégia de desenvolvimento rural". 4

No presente artigo, todavia, defende-se que as alternativas (de políticas públicas) propostas no referido Seminário para promover a pluriatividade basicamente as propostas se limitam ao fomento a atividades rurais não agrícolas não necessariamente redundarão nesse objetivo, uma vez que a pluriatividade fica desfocada do seu ponto mais crítico (o 'lado agrícola' da combinação 'agrícola

(4) É bem oportuno informar que, talvez como resultado dessa "chegada" da temática pluriatividade às instâncias públicas formuladoras de políticas para o meio rural, o próximo Censo Agropecuário, a ser realizado ainda neste ano, 2007, trará duas perguntas sobre pluriatividade abordando, ambas, acerca da participação do produtor agrícola (e/ou algum membro da família do produtor) em atividades econômicas (se agrícolas ou não agrícolas) fora do estabelecimento agropecuário, e se tais atividades são relevantes ou não para a renda familiar ou do estabelecimento. 
com não agrícola', que lhe é própria e definidora), conforme se busca mostrar ao longo do presente texto.

O objeto de análise deste artigo consiste, portanto, em explicar porque, ao contrário do que preconiza a ideia dominante na literatura - a qual se quer contribuir -, a pluriatividade no Brasil cresce no Nordeste - região pobre - e declina (ou tende a não crescer) na Região Sul. Ou seja, o presente artigo se ocupa em questionar e relativizar a ideia prevalecente de que a pluriatividade encontra ambiente favorável em economias locais mais dinâmicas e modernas.

Entende-se que o equívoco das análises sobre a pluriatividade no Brasil se deve ao fato dessa temática importada não ter sido assimilada levando-se em consideração certas especificidades da realidade brasileira. Tais especificidades, que consideramos decisivas para a compreensão das perspectivas da pluriatividade no Brasil, são: a pobreza rural - intimamente ligada à pluriatividade no Nordeste e a insuficiência das políticas públicas voltadas para as áreas rurais, incapazes de conter a tendência de abandono das atividades agrícolas pelos pequenos produtores familiares, caso específico da Região Sul, que possui, de um lado, uma agricultura altamente moderna e, de outro, entornos rurais (redes urbanas) desenvolvidos do ponto de vista não agrícola, cuja dinâmica conjunta desses dois lados não favorece, ao contrário do que a literatura preconiza, o crescimento da pluriatividade nessa região, conforme será mostrado mais adiante.

Ademais, o estudo da pluriatividade em si mesmo não é o objeto de investigação deste trabalho, como o faz a literatura pertinente no Brasil. Mas, refere-se à evolução da pluriatividade no tempo; e, portanto, à perspectiva que ela tem (ou não) de crescer numa realidade como a brasileira.

A discussão proposta será realizada através de uma análise comparativa da evolução dos contingentes de famílias pluriativas entre as regiões Nordeste e Sul. Escolhemos essas duas regiões por duas razões elementares: primeiro, porque abrigam, juntas, aproximadamente $80,0 \%$ das famílias do universo da agricultura familiar nacional; segundo, porque correspondem - Nordeste, de um lado, e Sul, de outro - a extremos resultantes da "modernização conservadora" da agricultura do país.

Além dessa introdução, o texto encontra-se dividido em mais quatro seções. A primeira expõe os aspectos metodológicos adotados no trabalho. A segunda seção apresenta a análise dos dados empíricos relativos a duas séries temporais, 1992-1999 e 2001-2005. A discussão da temática da pluriatividade no Nordeste e no Sul será apresentada na terceira seção. Por fim, na última seção, serão tecidas as considerações finais. 


\section{A metodologia utilizada}

Os tipos de famílias aqui analisados são classificados pela posição na ocupação dos membros da família (empregador, conta-própria, assalariado, não ocupado) $^{5}$ e, em seguida, pelo ramo de atividade em que estão inseridos (agrícola, não agrícola, pluriativo). ${ }^{6}$ Essa tipologia de famílias é a mesma construída pelo Projeto Rurbano (IE/Unicamp).

As análises seguintes ficarão restritas ao conjunto de famílias 'contapróprias' e 'assalariados' residentes nas áreas rurais não metropolitanas, denominadas rural agropecuário. ${ }^{7}$ Justifica-se isso pelo fato de que, nas regiões Nordeste e Sul, todos os tipos de famílias definidos pela posição na ocupação (empregadoras, conta-próprias, assalariadas e não ocupadas) declararam residência, em sua grande maioria (uma média que varia entre 72,0\% e 79,0\%), em áreas não metropolitanas. Por outro lado, as áreas rurais agropecuárias concentraram as famílias rurais não metropolitanas (variando a proporção, na média, entre 85,0\% no total geral das áreas rurais não metropolitanas em cada uma das duas regiões em análise). A maior concentração de famílias residentes em áreas rurais agropecuárias é de famílias conta-próprias e assalariadas (variando entre as regiões numa média de, ambas somadas, $84,0 \%$ do total de famílias) em 1999 (e em 2005 mantêm-se essas proporções com variações inexpressivas).

Considera-se como o universo da agricultura familiar a soma dos tipos de famílias de 'empregadores' (com até 2 empregados) e de 'conta-próprias' - ambos agrícolas e pluriativos. No entanto, em virtude deste trabalho se concentrar nos tipos 'conta-próprias' e 'assalariados', nosso universo identificado com a agricultura familiar restringe-se ao conjunto de famílias conta-próprias (agrícolas e

(5) Se na família houver algum membro empregador, tal família é classificada como empregadora. Não havendo nenhum empregador, mas pelo menos um conta-própria, a família é compreendida como de contaprópria. Na ausência de empregador e de conta-própria, a família será considerada de assalariados caso algum membro esteja ocupado na semana de referência da PNAD como tal. Não havendo nenhum ocupado na família, a mesma é considerada como família de não ocupados.

(6) Se, por exemplo, numa família de conta-próprias houver pelo menos um membro ocupado na agricultura e nenhum outro fora da agricultura, então essa família é classificada como de conta-própria agrícola. Caso a referida família de conta-própria tivesse pelo menos um membro na atividade agrícola e pelo menos um outro ocupado em outro setor, essa seria uma família de conta-própria pluriativa - é considerado família de contaprópria pluriativa "tradicional" no caso de combinação de um conta-própria agrícola e um assalariado agrícola na mesma família (não consideramos pluriativa "tradicional" a família de assalariados que tem dois, ou mais, membros assalariados agrícolas). Se o caso fosse de pelo menos um membro ocupado fora da agricultura e nenhum outro na agricultura, essa seria uma família de conta-própria não agrícola. As mesmas combinações podem ser repetidas para as famílias de assalariados e de empregadores.

(7) As áreas censitárias consideradas rurais pela Pesquisa Nacional por Amostra de Domicílios (PNAD) -, compreendem cinco tipos: 1) área rural de extensão urbana; 2) aglomerado rural (povoado); 3) aglomerado rural núcleo; 4) aglomerado rural (outros); 5) área rural exclusive aglomerado rural. O rural agropecuário, portanto, é constituído pela soma dos números 3 e 5 . A idéia de separar o rural agropecuário é tentar reconstruir os espaços considerados predominantemente agrícolas que são por excelência espaços apropriados por um único dono (público ou privado). 
pluriativas). As observações posteriormente realizadas sobre "agricultura familiar e pluriatividade" não ficarão comprometidas, já que o percentual de famílias ${ }^{8}$ de 'empregadores com até 2 empregados' sobre o total ('empregador com até 2 empregados' mais 'conta-próprias'), na média das regiões aqui em análise (Nordeste e Sul), gira em torno de 4,5\%, em 1999 (e 7,0\%, em 2005). O que equivale a dizer que o percentual de famílias conta-próprias no universo da agricultura familiar gira em torno de 95,5\% (1999) e de 93,0\% (2005), isto é, um contingente altamente representativo das análises realizadas a seguir.

Finalmente, todas as informações empíricas aqui apresentadas são derivadas do processamento dos microdados da Pesquisa Nacional por Amostra de Domicílios do IBGE (PNAD/IBGE). Conforme será notado, trabalhou-se com duas séries de tempo, 1992 a 1999 e 2001 a 2005. A razão disso é que a PNAD não permite adotar uma série única englobando duas décadas (por exemplo, 1992 a 2005) quando se analisa apenas as áreas rurais ou as áreas urbanas. O problema é que o 'rural' da década de 1990 não é o mesmo da década de 2000. A cada Censo Demográfico (CD), o IBGE atualiza os limites urbanos dos municípios, que foram sendo alterados ao longo de cada década precedente. O CD 2000 efetuou tal correção, e as PNADs da presente década passaram a adotar os novos limites das áreas censitárias, tornando incompatíveis, portanto, os dois 'rurais', uma vez que uma parcela da população rural nas PNADs dos anos 1990 pode ter sido incorporada à população urbana nas PNADs dos anos 2000 por uma mera questão de resolução administrativa dos poderes legislativos municipais.

\section{Análise dos resultados do processamento dos microdados da PNAD}

\subsection{Anos 1990 (1992-1999): crescimento e persistência da pluriatividade em meio à pobreza rural nordestina e tendência ao não crescimento da pluriatividade no Sul do Brasil}

Comparando a evolução do contingente dos diferentes tipos de famílias pluriativas nordestinas com suas congêneres sulinas (Tabela 1), pode-se verificar que, a despeito da relativa estabilidade do período 1992/1999, no período 1995 a 1999 - períodos de intensificação da crise agrícola que recaiu sobre os pequenos produtores rurais, especialmente sulinos (conforme Nascimento, 2006) - houve crescimento significativo 9 (8,5\% a.a.) das famílias conta-próprias pluriativas

(8) Famílias rurais agropecuárias não metropolitanas.

(9) O qualificativo significativo concerne ao teste estatístico feito para verificar se a evolução dos dados (número de famílias) apresenta alguma tendência de crescimento ou de queda. Dessa forma, sempre que for usado, doravante, esse qualificativo (representado pelos asteriscos que acompanham algumas taxas nas Tabelas) a intenção será de mostrar que os dados apresentam uma certa tendência estatística, de modo que, nos casos em que as taxas de crescimento das Tabelas não estiverem acompanhadas de asteriscos, significará que as mesmas não são estatisticamente significativas e, portanto, não representam nenhuma tendência - o que poderá ser traduzido, por conseguinte, como uma estabilidade dos dados. 
intersetoriais $^{10}$ exclusivamente na Região Nordeste. Na Região Sul, nenhum tipo de família conta-própria pluriativa (que faz parte do contingente da agricultura familiar da região) apresentou tendência positiva de crescimento nos períodos 1992/1999 e 1995/1999; pelo contrário, quase todas as taxas de crescimento são negativas, ainda que algumas sejam não significativas (no sentido estatístico).

Tabela 1

Distribuição e taxas de crescimento dos tipos de famílias segundo o local de domicílio e região: 1992/99 e 1995/99. (1.000 famílias)

\begin{tabular}{|c|c|c|c|c|c|c|}
\hline \multirow{4}{*}{$\begin{array}{l}\text { Local Domicílio / } \\
\text { Tipo de Família }\end{array}$} & $\mathrm{NE}$ & Sul & Nordeste & Sul & Nordeste & Sul \\
\hline & \multirow{2}{*}{ Mil fam } & \multirow{2}{*}{ Mil fam } & tx cresc. & tx cresc. & tx cresc. & tx cresc. \\
\hline & & & (\% aa.) & (\% aa.) & (\% aa.) & (\% aa.) \\
\hline & 1999 & 1999 & $1992 / 99^{a}$ & $1992 / 99^{a}$ & $1995 / 99^{a}$ & $1995 / 99^{a}$ \\
\hline \multicolumn{7}{|l|}{ Não Metropolitano } \\
\hline \multicolumn{7}{|l|}{ Rural Agropecuário } \\
\hline Conta-Própria & 1799 & 671 & $1,6^{* *}$ & $-2,0 * * *$ & 1,9 & $-2,0 * * *$ \\
\hline Agrícola & 1015 & 467 & 1,7 & $-2,9 * * *$ & $-0,4$ & $-2,6 * * *$ \\
\hline Pluriativo & 653 & 138 & 0,7 & $-2,2 * *$ & 5,4 & $-2,8$ \\
\hline $\begin{array}{l}\text { Tradicional (Agrícola } \\
\text { com Agrícola) }\end{array}$ & 199 & 27 & 1,8 & $-4,0 * * *$ & $-0,5$ & $-5,5 * * *$ \\
\hline $\begin{array}{l}\text { Intersetorial (Agr. } \\
\text { Com Não-Agríc.) }\end{array}$ & 455 & 109 & 0,5 & $-1,8$ & $8,5^{*}$ & $-2,5$ \\
\hline Não-agrícola & 131 & 67 & $5,9 * * *$ & $9,4 * * *$ & 3,9 & 5,9 \\
\hline Assalariados & 852 & 428 & $-0,1$ & $3,2 * * *$ & $2,6^{*}$ & $4,4 * * *$ \\
\hline Agrícola & 462 & 185 & $-2,6^{*}$ & 0,5 & $-4,8$ & 1,3 \\
\hline Pluriativo & 161 & 42 & 1,4 & $-1,0$ & $16,9 *$ & $-3,8$ \\
\hline Não-agrícola & 230 & 201 & $5,8^{*}$ & $7,6^{* * * *}$ & $12,5^{*}$ & $10,1 * * *$ \\
\hline
\end{tabular}

Nota: exclusive as famílias sem declaração de renda e tipos de família com menos de 6 observações

a) estimativa do coeficiente de uma regressão log-linear contra o tempo. Neste caso, o teste t indica a existência ou não de uma tendência nos dados. ***, **, * significam respectivamente $5 \%$, $10 \%$ e $20 \%$.

Fonte: PNAD - Tabulações Especiais do Projeto Rurbano, IE/Unicamp, Elaboração própria.

A Tabela 2, por sua vez, compara, respectivamente, a evolução $(1995 / 1999),{ }^{11}$ em termos de taxas de crescimento, e a proporção ${ }^{12}$ de famílias

(10) A pluriatividade intersetorial é aquela em que a família tem pelo menos um membro ocupado em uma atividade agrícola e pelo menos outro ocupado em uma atividade não agrícola. Por sua vez, a pluriatividade tradicional consiste na família que concilia, entre seus membros, 'trabalho agrícola por conta-própria com assalariamento agrícola'.

(11) O deflator usado é o INPC (restrito), o mesmo índice deflator utilizado pelo IBGE para comparar os resultados das PNADs. Importa notificar que optamos por considerar apenas a série 1995/1999 e desconsiderar os anos 1992 e 1993 para as tabelas de famílias pobres, com a intenção de evitarmos incorrer em erros graves, posto que parte do crescimento das rendas captado pelas PNADs de 1992 a 1995 se deve ao fato de que o deflator utilizado pode não ter captado adequadamente a inflação da época da implantação do Plano Real no ano de 1994.

(12) Proporção sobre o total de cada tipo familiar. 
pobres residentes nas áreas rurais agropecuárias das regiões Nordeste e Sul (com uma linha de pobreza correspondente à renda média familiar per capita de $1 / 2 \mathrm{~s} . \mathrm{m}$. em R \$ de set./1999) ${ }^{13}$ em 1999. Pode-se ver que é no Nordeste que as famílias rurais agropecuárias conta-próprias (agricultura familiar) pobres pluriativas intersetoriais crescem significativamente (9,4\% a.a.).

Tabela 2

Proporção, distribuição e taxas de crescimento dos tipos de famílias extensas pobres segundo o local de domicílio: 1992/99. (linha de pobreza: renda média per capita familiar de 1/2 s.m. em R \$ de set/1999) (1.000 famílias)

\begin{tabular}{|c|c|c|c|c|c|c|}
\hline \multirow{3}{*}{$\begin{array}{l}\text { Local Domicílio / } \\
\text { Tipo de Família }\end{array}$} & \multirow{2}{*}{$\begin{array}{l}\text { Nordeste } \\
\text { tx cresc. } \\
\text { (\% aa.) }\end{array}$} & \multirow{2}{*}{$\begin{array}{c}\text { Sul } \\
\text { tx cresc. } \\
(\% \text { aa. })\end{array}$} & \multicolumn{2}{|c|}{ Nordeste } & \multicolumn{2}{|c|}{ Sul } \\
\hline & & & $\begin{array}{l}\text { Mil fam } \\
\text { pobres }\end{array}$ & $\begin{array}{l}\% \text { fam } \\
\text { pobres } \\
\text { s/ total }\end{array}$ & $\begin{array}{c}\text { Mil } \\
\text { fam } \\
\text { pobres }\end{array}$ & $\begin{array}{l}\% \text { fam } \\
\text { pobres } \\
\text { s/ total }\end{array}$ \\
\hline & $1995 / 99^{a}$ & $1995 / 99^{a}$ & 1999 & 1999 & 1999 & 1999 \\
\hline \multicolumn{7}{|l|}{ Não Metropolitano } \\
\hline \multicolumn{7}{|l|}{ Rural Agropecuário } \\
\hline Conta-Própria & 1,7 & $-5,8 * * *$ & 1072 & 59,6 & 179 & 26,6 \\
\hline Agrícola & $-1,1$ & $-6,4 * * *$ & 616 & 60,7 & 151 & 32,4 \\
\hline Pluriativo & 6,5 & $-4,7$ & 392 & 60,1 & 18 & 13,1 \\
\hline $\begin{array}{l}\text { Tradicional (Agrícola com } \\
\text { Agrícola) }\end{array}$ & 1,1 & $-15,5^{*}$ & 124 & 62,6 & 5 & 17,2 \\
\hline $\begin{array}{l}\text { Intersetorial (Agr. Com } \\
\text { Não-agríc.) }\end{array}$ & $9,4^{*}$ & 1,2 & 268 & 59,0 & 13 & 12,1 \\
\hline Não-agrícola & 2,7 & 2,1 & 63 & 48,4 & 9 & 13,7 \\
\hline Assalariados & $2,3^{*}$ & 1,6 & 570 & 66,9 & 129 & 30,2 \\
\hline Agrícola & $-5,7$ & $-0,9$ & 324 & 70,1 & 82 & 44,3 \\
\hline Pluriativo & 16,5 & $-1,3$ & 105 & 65,3 & 9 & 20,9 \\
\hline Não-agrícola & $15,8^{* *}$ & $9,6 * * *$ & 141 & 61,4 & 38 & 19,1 \\
\hline
\end{tabular}

Nota: exclusive as famílias sem declaração de renda e tipos de famílias com menos de 6 observações.

a) estimativa do coeficiente de uma regressão log-linear contra o tempo. Neste caso, o teste t indica a existência ou não de uma tendência nos dados. ***, **, * significam respectivamente $5 \%, 10 \%$ e $20 \%$.

Fonte: PNAD - Tabulações Especiais do Projeto Rurbano, IE/Unicamp, Elaboração própria.

No Sul, diferentemente, a Tabela 2 evidencia basicamente a redução significativa $(15,5 \%)$ do efetivo das famílias conta-próprias pluriativas tradicionais (agrícola com agrícola) pobres, segundo a linha de pobreza adotada. Considerando que a Tabela 1 mostrou que houve uma queda significativa das famílias contapróprias pluriativas sulinas como um todo, pode-se cogitar que a pluriatividade não está evitando o aprofundamento da proletarização dessas famílias na Região

(13) O salário mínimo (s.m.) em set./1999 era de R\$ 136,00. 
Sul, uma vez que essas famílias não estão se tornando famílias conta-próprias pluriativas 'não pobres', ${ }^{14}$ que apresentaram taxas negativas de crescimento embora não significativas, conforme mostra a Tabela 3 , indicando que aquelas famílias podem estar deixando de ser conta-próprias e se tornando assalariadas.

$\mathrm{Na}$ Região Nordeste, o registro do crescimento significativo das famílias conta-próprias pluriativas intersetoriais pobres (Tabela 2), conforme já mencionado, indica que a pluriatividade não está contribuindo para retirar essas famílias de debaixo da linha de pobreza estipulada. Ou seja, a pluriatividade intersetorial ou tradicional, além de ser um sinal claro do processo de proletarização das unidades agrícolas familiares nordestinas, não está evitando o empobrecimento dessas famílias, ao contrário do que seria esperado pela literatura.

Tabela 3

Proporção, distribuição e taxas de crescimento dos tipos de famílias não pobres segundo o local de domicílio: 1992/99. (linha de pobreza: renda média per capita familiar de 1/2 s.m. em $\mathrm{R} \$$ de set/1999) (1.000 famílias)

\begin{tabular}{|c|c|c|c|c|c|c|}
\hline \multirow{3}{*}{$\begin{array}{l}\text { Local Domicílio / } \\
\text { Tipo de Família }\end{array}$} & \multirow{2}{*}{$\begin{array}{l}\text { Nordeste } \\
\text { tx cresc. } \\
\text { (\% aa.) }\end{array}$} & \multirow{2}{*}{$\begin{array}{l}\text { Sul } \\
\text { tx cresc. } \\
(\% \text { aa. })\end{array}$} & \multicolumn{2}{|c|}{ Nordeste } & \multicolumn{2}{|c|}{ Sul } \\
\hline & & & $\begin{array}{c}\text { Mil } \\
\text { fam } \\
\text { não } \\
\text { pobres }\end{array}$ & $\begin{array}{l}\% \text { fam } \\
\text { não } \\
\text { pob. s/ } \\
\text { total }\end{array}$ & $\begin{array}{c}\text { Mil fam } \\
\text { não } \\
\text { pobres }\end{array}$ & $\begin{array}{l}\text { \% fam } \\
\text { não } \\
\text { pob. s/ } \\
\text { total }\end{array}$ \\
\hline & $1995 / 99^{a}$ & $1995 / 99^{a}$ & 1999 & 1999 & 1999 & 1999 \\
\hline \multicolumn{7}{|l|}{ Não Metropolitano } \\
\hline \multicolumn{7}{|l|}{ Rural Agropecuário } \\
\hline Conta-Própria & 2,2 & $-0,4$ & 727 & 40,4 & 493 & 73,4 \\
\hline Agrícola & 0,7 & $-0,5$ & 398 & 39,3 & 315 & 67,6 \\
\hline Pluriativo & 3,9 & $-2,6$ & 261 & 39,9 & 120 & 86,9 \\
\hline $\begin{array}{l}\text { Tradicional (Agrícola } \\
\text { com Agrícola) }\end{array}$ & $-2,8$ & $-2,0$ & 74 & 37,4 & 23 & 82,8 \\
\hline $\begin{array}{l}\text { Intersetorial Total (Agr. } \\
\text { Com Não-agríc.) }\end{array}$ & 8,0 & $-2,7$ & 182 & 41,0 & 97 & 87,9 \\
\hline Não-agrícola & $4,9^{*}$ & 6,6 & 68 & 51,6 & 58 & 86,3 \\
\hline Empregados & 3,2 & $5,7 * *$ & 283 & 33,1 & 299 & 69,8 \\
\hline Agrícola & $-3,1 *$ & 3,5 & 138 & 29,9 & 103 & 55,7 \\
\hline Pluriativo & $17,8 * * *$ & $-4,2$ & 56 & 34,7 & 33 & 79,1 \\
\hline Não-agrícola & 8,0 & $10,2 * * *$ & 89 & 38,6 & 163 & 80,9 \\
\hline
\end{tabular}

Nota: exclusive as famílias sem declaração de renda e tipos de famílias com menos de 6 observações

a) estimativa do coeficiente de uma regressão log-linear contra o tempo. Neste caso, o teste t indica a existência ou não de uma tendência nos dados. $* * *, * *, *$ significam respectivamente $5 \%, 10 \%$ e $20 \%$.

Fonte: PNAD - Tabulações Especiais do Projeto Rurbano, IE/Unicamp, Elaboração própria.

(14) As famílias não pobres da Tabela 3 são o resultado da diferença entre o total de famílias (de cada tipo) e as famílias pobres (segundo a linha de pobreza de 1/2 salário mínimo per capita familiar). 
$\mathrm{Na}$ Tabela 4, pode-se notar as taxas de crescimento do contingente de famílias pobres da agricultura familiar (famílias conta-próprias agrícolas e pluriativas), segundo faixas de área dos estabelecimentos onde são exercidas as atividades agropecuárias. A Tabela 4 mostra que é na Região Nordeste, e somente nela, que se observa que a pluriatividade no agregado, em quase todos os estratos de tamanho de estabelecimentos, apresenta taxas de crescimento positivas e significativas (no sentido estatístico). Observe-se ainda que o crescimento significativo da pluriatividade nordestina no agregado se deve exclusivamente ao crescimento significativo das famílias pluriativas intersetoriais em quase todas as faixas de tamanho de estabelecimentos, uma vez que a pluriatividade tradicional (agrícola com agrícola) permaneceu estabilizada no mesmo período. No Sul, por sua vez, não se registra nenhum caso de crescimento significativo de famílias pobres no interior da agricultura familiar. Pelo contrário, todas as taxas significativas são de crescimento negativo na Região Sul.

Mais uma vez, os dados apontam para a seguinte constatação: tanto a pluriatividade intersetorial como a tradicional no Nordeste, além de serem ambas sinais de proletarização dos produtores familiares, não evitam o empobrecimento das famílias rurais da região. Ou seja, a pluriatividade no Nordeste do Brasil não está cumprindo o papel de evitar a combinação entre proletarização e empobrecimento. 
Tabela 4

Taxas de crescimento dos tipos de famílias extensas de conta-próprias pobres segundo o local de domicílio e tamanho de estabelecimento. 1995/99 (linha de pobreza: renda média per capita familiar de 1/2 s.m. em R \$ de set/1999)

\begin{tabular}{|c|c|c|c|c|c|c|c|}
\hline \multirow[t]{2}{*}{$\begin{array}{l}\text { Local Domicílio / } \\
\text { Tipo de Família }\end{array}$} & $\begin{array}{c}\text { menos de } 20 \\
\text { ha } \\
\text { (\% aa.) }\end{array}$ & $\begin{array}{c}\text { de } 20 \text { ha } \\
\text { a menos } \\
\text { de } 100 \text { ha } \\
\text { (\% aa.) }\end{array}$ & $\begin{array}{l}\text { de } 100 \text { ha } \\
\text { e mais. } \\
\text { (\% aa. })\end{array}$ & $\begin{array}{c}\text { menos de } \\
2 \text { ha } \\
\text { (\% aa.) }\end{array}$ & $\begin{array}{c}\text { de } 2 \text { ha a } \\
\text { menos de } \\
10 \text { ha } \\
\text { (\% aa.) }\end{array}$ & $\begin{array}{c}\text { de } 10 \text { ha a } \\
\text { menos de } \\
100 \text { ha } \\
(\% \text { aa. })\end{array}$ & $\begin{array}{c}\text { de } 100 \text { ha e } \\
\text { mais } \\
(\% \text { aa. })\end{array}$ \\
\hline & $1995 / 99^{a}$ & $1995 / 99^{a}$ & $1995 / 99^{a}$ & $1995 / 99^{a}$ & $1995 / 99^{a}$ & $1995 / 99^{a}$ & $1995 / 99^{a}$ \\
\hline
\end{tabular}

\section{Não-Metropolitano}

Rural Agropecuário

\begin{tabular}{|c|c|c|c|c|c|c|c|}
\hline \multicolumn{8}{|c|}{ Nordeste } \\
\hline Conta-próprias (agrícolas mais pluriativos) & $-0,7$ & $8,9 * *$ & 8,3 & $-3,5$ & $-0,3$ & $5,6^{*}$ & 8,3 \\
\hline Agrícola & $-4,1$ & 7,5 & 4,2 & $-5,1$ & $-3,4$ & 3,0 & 4,2 \\
\hline Tradicional (Agrícola com Agrícola) & $-0,5$ & 8,6 & 6,8 & $-8,6$ & 3,1 & 3,3 & 6,8 \\
\hline Intersetorial Total (Agr. com Não-agríc.) & $8,4 *$ & $13,2 *$ & $22,2 * * *$ & 3,1 & $8,3 *$ & $14,8 * * *$ & $22,2 * * *$ \\
\hline \multicolumn{8}{|c|}{ Sul } \\
\hline Agrícola & $-10,8 * *$ & $-5,1 * *$ & 0,5 & -- & $-15,7 *$ & $-6,0 * * *$ & 0,5 \\
\hline Pluriativo & $-20,1 * * *$ & 4,1 & -- & -- & -- & $-8,4$ & -- \\
\hline Tradicional (Agrícola com Agrícola) & -- & -- & -- & -- & -- & $-18,7 *$ & -- \\
\hline Intersetorial Total (Agr. com Não-agríc.) & $-15,2$ & 4,1 & -- & -- & -- & $-2,4$ & -- \\
\hline
\end{tabular}

Nota: exclusive as famílias sem declaração de renda e tipos de famílias com menos de 6 observações

Os ". -" indicam que o tamanho da amostra não é significativo (menos de 6 casos)

a) estimativa do coeficiente de uma regressão log-linear contra o tempo. Neste caso, o teste t indica a existência ou não de uma tendência nos dados. $* * *, * *, *$ significam respectivamente $5 \%, 10 \%$ e $20 \%$.

Fonte: PNAD - Tabulações Especiais do Projeto Rurbano, IE/Unicamp, Elaboração própria. 
Reforçando as considerações até aqui tecidas, as Tabelas 5 e 6 apresentam taxas de crescimento das famílias de conta-próprias ${ }^{15}$ agrícolas e pluriativas (agricultura familiar) segundo faixas de tamanho de área dos estabelecimentos onde exercem as atividades agropecuárias nos períodos analisados (1992/1999 e 1995/1999). Nessas tabelas, pode-se ver que, com exceção da faixa de 'menos de 2 ha', em todas as demais faixas, é na região Nordeste que mais ocorrem expressivas taxas positivas e significativas (no sentido estatístico) de crescimento dos dois tipos de famílias pluriativas - sobretudo, a pluriatividade intersetorial das famílias nordestinas -, em ambos os períodos abordados.

No Sul, por sua vez, não se nota um único caso de crescimento da pluriatividade em nenhum dos dois períodos analisados. Há registros de queda significativa (no sentido estatístico) da pluriatividade sulina total puxada tanto pela pluriatividade tradicional como pela pluriatividade intersetorial (Tabela 6). Em geral, as taxas de crescimento das famílias conta-próprias (agricultura familiar: agrícolas mais pluriativos) sulinas são negativas. Observe-se, portanto, que a agricultura familiar sulina decresce em quase todos os estratos de área - exceto o de 100 ha e mais ${ }^{16}$-, e a pluriatividade não contribui para evitar essa tendência, pelo contrário. Ou seja, no Sul do país a pluriatividade tende a se reduzir juntamente com o conjunto da agricultura familiar da região.

Em relação à Região Nordeste, ambas as tabelas mostram que, em quase todos os estratos de tamanho de estabelecimentos familiares, o contingente da agricultura familiar nordestina total (conta-próprias agrícolas mais pluriativos) cresceu significativamente. Essa mesma observação pode ser feita em relação às famílias nordestinas pluriativas, especialmente a pluriatividade intersetorial ('agrícola com não agrícola') em ambos os períodos em análise (1992/1999 e 1995/1999).

(15) O conjunto de pobres mais não pobres.

(16) Homem de Melo (1999 e 2001), um dos autores em que nos apoiamos em Nascimento (2005a), considera familiar apenas os estabelecimentos com menos de 100 hectares. 
Tabela 5

Taxas de crescimento dos tipos de famílias de conta-próprias, segundo o local de domicílio e faixa de área. 1992/1999 e 1995/1999

\begin{tabular}{|c|c|c|c|c|c|c|c|c|}
\hline \multirow{3}{*}{$\begin{array}{l}\text { Local Domicílio / } \\
\text { Tipo de Família }\end{array}$} & $\begin{array}{l}\text { menos } \\
\text { de } 2 \text { ha }\end{array}$ & $\begin{array}{c}\text { de } 2 \text { ha a } \\
\text { menos de } \\
10 \text { ha }\end{array}$ & $\begin{array}{c}\text { de } 10 \text { ha a } \\
\text { menos de } \\
100 \text { ha }\end{array}$ & $\begin{array}{c}\text { de } 100 \text { ha } \\
\text { e mais }\end{array}$ & $\begin{array}{l}\text { menos } \\
\text { de } 2 \text { ha }\end{array}$ & $\begin{array}{c}\text { de } 2 \text { ha a } \\
\text { menos de } \\
10 \text { ha }\end{array}$ & $\begin{array}{c}\text { de } 10 \text { ha a } \\
\text { menos de } \\
100 \text { ha }\end{array}$ & $\begin{array}{l}\text { de } 100 \text { ha } \\
\text { e mais }\end{array}$ \\
\hline & $\begin{array}{l}\text { tx cresc. } \\
(\% \text { aa. })\end{array}$ & $\begin{array}{c}\text { tx cresc. } \\
(\% \text { aa. })\end{array}$ & $\begin{array}{c}\text { tx cresc. } \\
(\% \text { aa. })\end{array}$ & $\begin{array}{l}\text { tx cresc. } \\
(\% \text { aa. })\end{array}$ & $\begin{array}{l}\text { tx cresc. } \\
(\% \text { aa. })\end{array}$ & $\begin{array}{r}\text { tx cresc. } \\
(\% \text { aa. })\end{array}$ & $\begin{array}{r}\text { tx cresc. } \\
(\% \text { aa. })\end{array}$ & $\begin{array}{r}\text { tx cresc. } \\
(\% \text { aa. })\end{array}$ \\
\hline & \multicolumn{2}{|c|}{$1992 / 99^{a} 1992 / 99^{a}$} & $1992 / 99^{a}$ & \multicolumn{4}{|c|}{$1992 / 99^{\mathrm{a}} 1995 / 99^{\mathrm{a}} 1995 / 99^{\mathrm{a}} 1995 / 99^{\mathrm{a}}$} & $1995 / 99^{a}$ \\
\hline
\end{tabular}

Não Metropolitano

Rural Agropecuário

\begin{tabular}{|c|c|c|c|c|c|c|c|c|}
\hline \multicolumn{9}{|c|}{ Nordeste } \\
\hline Conta-próprias (agrícolas mais pluriativos) & 1,4 & $2,0 *$ & $4,3 * * *$ & $5,9 * * *$ & $-4,6$ & $-0,3$ & $6,3 * * *$ & $6,9 *$ \\
\hline Agrícola & 0,5 & 2,6 & $4,6 * *$ & $6,7 * * *$ & $-6,7$ & $-3,2$ & 4,9 & 7,2 \\
\hline Pluriativo & 2,6 & 0,9 & $3,9 *$ & $4,0 * * *$ & $-1,5$ & $7,9 * *$ & $9,1 * *$ & $6,9 * *$ \\
\hline Tradicional (Agrícola com Agrícola) & 3,8 & $6,1 * * *$ & 2,5 & -- & $-6,5$ & 2,3 & 0,8 & $-4,2$ \\
\hline Intersetorial Total (Agr. com Não-agríc.) & 1,9 & 0,9 & $4,8 *$ & $3,3 * * *$ & 1,5 & $7,9 * *$ & $12,9 * *$ & $11,3^{*}$ \\
\hline \multicolumn{9}{|c|}{ Sul } \\
\hline Conta-próprias (agrícolas mais pluriativos) & $-7,6$ & $-6,8 * * *$ & $-2,8 * * *$ & $2,9 * *$ & 3,0 & $-9,0 * *$ & $-3,1 * * *$ & $5,3 *$ \\
\hline Agrícola & -- & $-8,6 * * *$ & $-3,3 * * *$ & $5,3 * * *$ & -- & $-9,7 * *$ & $-3,3 * * *$ & $7,6^{* *}$ \\
\hline Pluriativo & -- & $-1,0$ & $-1,0$ & $-9,4 * * *$ & -- & $-7,0$ & $-2,0$ & $-8,3$ \\
\hline Tradicional (Agrícola com Agrícola) & -- & -- & $-4,1 * * *$ & -- & -- & -- & $-7,0 * * *$ & -- \\
\hline Intersetorial Total (Agr. com Não-agríc.) & -- & $-1,0$ & $-0,1$ & -- & -- & $-7,0$ & $-0,7$ & -- \\
\hline
\end{tabular}

Nota: exclusive as famílias sem declaração de renda e tipos de famílias com menos de 6 observações

Os " - -" indicam que o tamanho da amostra não é significativo (menos de 6 casos)

a) estimativa do coeficiente de uma regressão log-linear contra o tempo. Neste caso, o teste t indica a existência ou não de uma tendência nos dados.

$* * *, * *, *$ significam respectivamente $5 \%, 10 \%$ e $20 \%$.

Fonte: Microdados da PNAD - Tabulações Especiais do Projeto Rurbano, IE/Unicamp. 
Tabela 6

Taxas de crescimento dos tipos de famílias extensas de conta-próprias, segundo o local de domicílio e faixa de área. 1992/1999 e 1995/1999

\begin{tabular}{c|c|c|c|c|c|c}
\hline \multirow{2}{*}{$\begin{array}{c}\text { Local Domicílio / } \\
\text { Tipo de Família }\end{array}$} & $\begin{array}{c}\text { Menos } \\
\text { de } 20 \text { ha }\end{array}$ & $\begin{array}{c}\text { de } 20 \text { ha a } \\
\text { menos de } \\
100 \text { ha }\end{array}$ & $\begin{array}{c}\text { de } 100 \text { ha e } \\
\text { mais }\end{array}$ & $\begin{array}{c}\text { menos } \\
\text { de } 20 \text { ha }\end{array}$ & $\begin{array}{c}\text { de } 20 \text { ha a } \\
\text { menos de } \\
100 \text { ha }\end{array}$ & $\begin{array}{c}\text { de } 100 \text { ha e } \\
\text { mais }\end{array}$ \\
\cline { 2 - 8 } & $\begin{array}{c}\text { tx cresc. } \\
(\% \text { aa. })\end{array}$ & $\begin{array}{c}\text { tx cresc. } \\
(\% \text { aa. })\end{array}$ & $\begin{array}{c}\text { tx cresc. } \\
(\% \text { aa. })\end{array}$ & $\begin{array}{c}\text { tx cresc. } \\
(\% \text { aa. })\end{array}$ & $\begin{array}{c}\text { tx cresc. } \\
(\% \text { aa. })\end{array}$ & $\begin{array}{c}\text { tx cresc. } \\
(\% \text { aa. })\end{array}$ \\
\hline & $1992 / 99^{a}$ & $1992 / 99^{\text {a }}$ & $1992 / 99^{\text {a }}$ & $1995 / 99^{\text {a }}$ & $1995 / 99^{\text {a }}$ & $1995 / 99^{\text {a }}$ \\
\hline
\end{tabular}

Não Metropolitano

Rural Agropecuário

\begin{tabular}{|c|c|c|c|c|c|c|}
\hline \multicolumn{7}{|c|}{ Nordeste } \\
\hline Conta-próprias (agrícolas mais pluriativos) & $2,3 *$ & $5,7 * * *$ & $5,9 * * *$ & 0,0 & $7,7 * * *$ & $6,9^{*}$ \\
\hline Agrícola & 2,0 & $6,0 * * *$ & $6,7 * * *$ & $-3,1$ & $6,7 *$ & 7,2 \\
\hline Pluriativo & $2,7 *$ & $5,0 *$ & $4,0 * * *$ & 5,3 & $10,7 *$ & $6,9 * *$ \\
\hline Tradicional (Agrícola com Agrícola) & $5,1 * *$ & 1,8 & -- & 0,4 & $-0,6$ & $-4,2$ \\
\hline Intersetorial Total (Agr. com Não-agríc.) & 1,8 & 5,0 & 3,3 & $8,0 *$ & $10,7 *$ & $11,3^{*}$ \\
\hline
\end{tabular}

Sul

\begin{tabular}{l|r|r|r|r|r|r}
\hline Conta-próprias (agrícolas mais pluriativos) & $-7,1 * * *$ & $-1,7 * * *$ & $2,9 * *$ & $-6,3 * *$ & $-2,5 * *$ & $5,3 *$ \\
\hline Agrícola & $-8,0 * * *$ & $-2,2 * * *$ & $5,3 * * *$ & $-6,8 * * *$ & $-3,0 * *$ & $7,6 * *$ \\
\hline Pluriativo & $-4,7 * * *$ & 1,4 & $-9,4 * * *$ & $-5,1$ & $-0,1$ & $-8,3$ \\
\hline Tradicional (Agrícola com Agrícola) & $-8,7 * * *$ & $-2,8$ & -- & $-5,3$ & $-7,8$ & -- \\
\hline Intersetorial Total (Agr. com Não-agríc.) & $-3,4 *$ & 1,4 & $-9,4 * * *$ & $-4,8$ & $-0,1$ & $-8,3$ \\
\hline
\end{tabular}

Nota: exclusive as famílias sem declaração de renda e tipos de famílias com menos de 6 observações

Os “- -" indicam que o tamanho da amostra não é significativo (menos de 6 casos)

a) estimativa do coeficiente de uma regressão log-linear contra o tempo. Neste caso, o teste t indica a existência ou não de

uma tendência nos dados. $* * *, * *, *$ significam respectivamente $5 \%, 10 \%$ e $20 \%$.

Fonte: Microdados da PNAD - Tabulações Especiais do Projeto Rurbano, IE/Unicamp 


\subsection{Primeiros anos do século XXI (2001-2005): mantêm-se as tendências anteriores}

A Tabela $7^{17}$ mostra que, do ponto de vista estatístico, a pluriatividade manteve-se, entre as famílias de conta-próprias (agricultura familiar), estável tanto no Nordeste quanto no Sul no período 2001 a 2005. Nesse novo período de análise, continua em declínio o número de famílias conta-próprias agrícolas - o que pode também ser verificado nas Tabelas anteriores, notadamente na Região Sul. Observa-se ainda que aumentou significativamente o contingente de famílias de assalariados nas duas regiões, o que pode sugerir que as famílias de contapróprias agrícolas podem estar se convertendo (tendencialmente; sentido estatístico) em famílias de assalariados, e não em famílias pluriativas (Tabela 7).

Tabela 7

Distribuição e taxas de crescimento dos tipos de famílias, segundo o local de domicílio e Regiões, 2001-2005. (1.000 famílias)

\begin{tabular}{|c|c|c|c|c|}
\hline \multirow{4}{*}{$\begin{array}{l}\text { Local Domicílio / } \\
\text { Tipo de Família }\end{array}$} & \multicolumn{2}{|c|}{ Nordeste } & \multicolumn{2}{|c|}{ Sul } \\
\hline & \multirow{3}{*}{2005} & tx cresc. & \multirow{3}{*}{2005} & tx cresc. \\
\hline & & (\% aa.) & & (\% aa.) \\
\hline & & $2001 / 2005^{a}$ & & $2001 / 2005^{a}$ \\
\hline \multicolumn{5}{|l|}{ Não Metropolitano } \\
\hline \multicolumn{5}{|l|}{ Rural Agropecuário } \\
\hline Conta-Própria & 1513 & $-0,7$ & 669 & $-1,0$ \\
\hline Agrícola & 771 & $-3,1^{*}$ & 446 & $-3,0 * * *$ \\
\hline Pluriativo & 603 & 1,3 & 170 & 3,9 \\
\hline Não-agrícola & 139 & $8 *$ & 53 & 2,1 \\
\hline Assalariados & 952 & $4,2 * * *$ & 363 & $2,8 * * *$ \\
\hline Agrícola & 620 & $3,6 * *$ & 154 & 2,1 \\
\hline Pluriativo & 122 & $5,1 * *$ & 46 & 0,9 \\
\hline Não-agrícola & 211 & 5,4 & 164 & 4,2 \\
\hline Não-ocupados na semana & 362 & 2,8 & 123 & 0,0 \\
\hline Total & 2934 & $1,3 * * *$ & 1232 & $0,5 * * *$ \\
\hline
\end{tabular}

Nota: exclusive as famílias sem declaração de renda e tipos de família com menos de 6 observações

a) estimativa do coeficiente de uma regressão log-linear contra o tempo. Neste caso, o teste $\mathrm{t}$ indica a existência ou não de uma tendência nos dados. $* * *, * *$, * significam respectivamente $5 \%, 10 \%$ e $20 \%$.

Fonte: PNAD - Tabulações Especiais do Projeto Rurbano, IE/Unicamp, Elaboração própria.

(17) Conforme já explicado com mais detalhes na seção sobre a metodologia adotada, convém lembrar que o motivo pelo qual não se fez uma série de tempo única (1992-2005) reside no fato de que o 'rural' das PNADs da presente década não é o mesmo da década de 1990. 
Por outro lado, observando-se o comportamento da agricultura familiar das duas regiões de uma forma mais desagregada, por faixas de tamanho de estabelecimentos, pode-se ver, na Tabela 8, que apenas a Região Nordeste apresenta taxa positiva de crescimento significativa da pluriatividade - e, note-se, que esse crescimento ocorreu no estrato de tamanho dos estabelecimentos de menos de 20 hectares, o que reforça as observações feitas na seção anterior acerca da relação entre famílias nordestinas pobres e crescimento da pluriatividade, sugerindo que, no Nordeste, parte das famílias agrícolas tenha se convertido em famílias pluriativas - o que os dados não sugerem em relação ao Sul (considerando a tendência estatística). A pluriatividade decresce significativamente apenas no estrato superior (100 ha e mais), estrato de área que abriga a menor proporção de unidades familiares, nas duas regiões $-2,9 \% \mathrm{em}$ cada. No Sul, nos demais estratos, a pluriatividade permaneceu estável (sentido estatístico), conforme já mencionado.

Tabela 8

Distribuição e taxas de crescimento dos tipos de famílias, segundo o local de domicílio, faixas de tamanho de estabelecimento e Regiões, 2001-2005. (1.000 famílias)

\begin{tabular}{|c|c|c|c|c|}
\hline \multirow{4}{*}{$\begin{array}{l}\text { Local Domicílio / } \\
\text { Tipo de Família }\end{array}$} & \multicolumn{2}{|c|}{ Nordeste } & \multicolumn{2}{|c|}{ Sul } \\
\hline & \multirow{3}{*}{2005} & tx cresc. & \multirow{3}{*}{2005} & tx cresc. \\
\hline & & (\% aa.) & & (\% aa.) \\
\hline & & $2001 / 2005^{a}$ & & $2001 / 2005^{a}$ \\
\hline \multicolumn{5}{|l|}{ Não Metropolitano } \\
\hline \multicolumn{5}{|l|}{ Rural Agropecuário } \\
\hline \multicolumn{5}{|l|}{ Conta-Própria } \\
\hline Menos de 20ha & 1004 & $-0,2$ & 374 & $-1,2$ \\
\hline Agrícola & 599 & $-2,4$ & 273 & $-3,3 * *$ \\
\hline Pluriativo & 405 & $3,6^{* *}$ & 101 & 5,7 \\
\hline De 20 ha a menos de 100 ha & 165 & $-3,0$ & 184 & $-1,6$ \\
\hline Agrícola & 95 & $-4,8$ & 145 & $-2,6^{*}$ \\
\hline Pluriativo & 70 & $-0,3$ & 39 & 2,5 \\
\hline De 100 ha a mais & 35 & $-8,9$ & 17 & $-3,2$ \\
\hline Agrícola & 23 & 0,0 & 13 & $-1,1$ \\
\hline Pluriativo & 12 & $-18,8 * *$ & 4 & $-10,1^{*}$ \\
\hline Total & 1204 & $-0,9$ & 575 & $-1,4$ \\
\hline
\end{tabular}

Nota: exclusive as famílias sem declaração de renda e tipos de família com menos de 6 observações a) estimativa do coeficiente de uma regressão log-linear contra o tempo. Neste caso, o teste t indica a existência ou não de uma tendência nos dados. ***, **, * significam respectivamente $5 \%, 10 \%$ e $20 \%$.

Fonte: PNAD - Tabulações Especiais do Projeto Rurbano, IE/Unicamp, Elaboração própria. 


\section{Discussão dos dados apresentados}

As explicações plausíveis para esses resultados não são, nem poderiam ser, idênticas para as duas regiões em análise, Nordeste e Sul. No caso da Região Nordeste, o crescimento da pluriatividade está associado ao atraso econômico da maior parte da região e à pobreza disseminada no interior da mesma. Ao contrário da Região Sul, onde predomina o modelo agrícola através do qual modernas tecnologias são aplicadas na agricultura (em todos os estratos de tamanhos, físicos e econômicos, de estabelecimentos rurais, segundo pode ser visto em Nascimento, 2006), no Nordeste, ainda predomina a prática de uma agricultura tradicional ou mesmo rudimentar (Hoffmann, 1992; Figueiredo; Hoffmann, 1998). De maneira geral, a despeito da presença de certas ilhas de modernização de uma agricultura não tradicional, como a agricultura irrigada nos "novos sertões" (Maia Gomes, 2001), ainda é predominante o atraso tecnológico da agricultura na Região Nordeste, "mesmo quando se trata de unidades da Federação que apresentam condições edáficas propícias à exploração de vários tipos de culturas agrícolas e regime pluviométrico regular na maior parte da sua extensão territorial, como é o caso do Estado do Maranhão" (Souza; Khan, 2001).

É, em grande medida, essa situação de atraso tecnológico que explica a capacidade que a agricultura de subsistência tem para absorver a mão-de-obra excedente no campo nordestino. É sob essas condições que a pobreza se reproduz entre as famílias das áreas rurais da região. E é essa pobreza que induz as famílias a diversificarem suas atividades; porém, as possibilidades de diversificação de atividades existem, mas em economias locais (redes urbanas) também bastante precarizadas, de modo que não se justifica a substituição de uma atividade (agrícola) por outra (não agrícola), uma vez que ambas são precárias. ${ }^{18}$

É, portanto, essa combinação de setores econômicos precarizados (geradores de ocupações e empregos também precarizados) que, do nosso ponto de vista, faz a pluriatividade crescer (e persistir crescendo) na Região Nordeste, contrariamente ao que ocorre na Região Sul. Ou seja, no Nordeste, o enfrentamento das famílias rurais agropecuárias às condições de pobreza ${ }^{19}$ leva-as à diversificação de suas fontes de ocupação e renda em setores de atividade de baixo dinamismo econômico. Portanto, a pluriatividade resultante dessa luta

(18) Através dos microdados do Censo Demográfico de 2000, é possível ver que entre 84,0\% e 86,0\% das famílias aqui analisadas encontravam-se residindo em municípios com menos de 50 mil habitantes (Nascimento, 2005a). No caso do Nordeste, diferentemente do Sul, são esses os municípios que o estudo do IPEA/IBGE/NESUR (2001) desprezou por considerar que são municípios cujas características os desqualificam para efeito das análises das dinâmicas econômicas das redes urbanas regionais, assim como para a análise das mudanças nas bases produtivas regionais e dos impactos de suas trajetórias econômicas e de suas mudanças espaciais sobre a estruturação da rede urbana.

(19) Em torno de $65 \%$ dessas famílias encontravam-se abaixo da linha de pobreza definida pela renda familiar média per capita de 1⁄2 salário mínimo em R \$ de setembro de 1999. 
cotidiana, recorrente, é uma pluriatividade que se adapta a uma realidade de pobreza. E é uma pobreza adaptativa às condições econômicas da região que secularmente se reproduz sem grandes saltos - pelo menos quanto aos seus efeitos irradiadores para o interior da região (Carvalho, 2001). Nesse mesmo sentido, a pluriatividade, enquanto estratégia de sobrevivência nessa realidade de pobreza, também é adaptativa a essa economia estática (no sentido schumpeteriano), adaptativa à pobreza recorrente. Uma economia de numerosos pequenos municípios com uma pobreza generalizada (IPEA/IBGE/NESUR, 2001), marcados pela ausência de descontinuidades na sua dinâmica reprodutiva.

Desse modo, é essa longa continuidade, perpetuando o sistema econômico da região, com a predominância de grandes frações dos setores econômicos em estado precário (arcaicos, rudimentares), que faz crescer adaptativamente a pobreza entre as famílias da região e, junto com ela, a pluriatividade com que se confunde. Portanto, pluriatividade e pobreza andam de mãos dadas nas áreas rurais da Região Nordeste. Excelentes referências de Estudos de Caso que confirmam essas considerações são os trabalhos de Alves (2002) e Alves; Valente Jr. e Brainer $(2005,2006)$ - pesquisadores do ETENE/BNB.

Antes de se apresentar a explicação para a Região Sul, convém esclarecer que a família pluriativa (que genericamente chamamos de pluriatividade) possui duplo caráter por estar, a um só tempo, ligada, por um lado, a atividades agrícolas e, por outro lado, a outros setores da atividade econômica não agrícola. Essa dupla forma de inserção na atividade econômica está condicionada a uma dupla determinação. Uma, associada ao que doravante chamaremos de o 'lado não agrícola' $^{20} \mathrm{e}$, outra, vinculada ao que, de agora em diante, denominaremos de o 'lado agrícola'. ${ }^{21}$ A combinação do 'lado agrícola' com o 'lado não agrícola' conforma a pluriatividade, que inexiste na ausência de um desses lados e que, portanto, ocorrendo o declínio de um dos lados, por exemplo, o 'lado agrícola', resultará em declínio da pluriatividade. Em outras palavras, para deixar mais claro o raciocínio, no caso das famílias rurais pluriativas - que combinam entre seus membros atividades agrícolas e não agrícolas - virem, por alguma razão, a abandonar as atividades agrícolas (o 'lado agrícola'), aquelas tornar-se-ão famílias rurais não agrícolas, uma vez que a literatura pertinente não considera pluriativas

(20) O 'lado não agrícola' dos determinantes da pluriatividade diz respeito basicamente a todo tipo de oportunidade existente para a inserção de membros de famílias agrícolas nos mercados de trabalho não agrícolas, seja nas próprias áreas rurais, seja nos seus entornos (economias locais/regionais), seja em áreas mais distantes a partir das quais os membros da família enviam parte de suas rendas para complementar a renda familiar.

(21) O 'lado agrícola' dos determinantes da pluriatividade concerne à possibilidade, à capacidade, da família agricultora de preservar seu vínculo a uma atividade agrícola. Entende-se, neste trabalho, que tal capacidade, para uma grande fração de unidades de produtores familiares agrícolas, depende do apoio do Estado, de políticas públicas. 
as famílias ocupadas apenas em atividades não agrícolas, por mais diversificadas que sejam.

Por definição, só existe pluriatividade entre famílias (de conta-próprias e de assalariados) cujos membros conciliam entre si ocupações em atividades agrícolas e não agrícolas (pluriatividade intersetorial) ou entre famílias de contapróprias em que algum membro se ocupa em outro estabelecimento agrícola por assalariamento (pluriatividade tradicional). Por essa razão, o crescimento do contingente de famílias pluriativas pressupõe o crescimento de famílias com algum membro ocupado em uma atividade agrícola ou, pelo menos, a preservação das famílias agrícolas que já existem e que passam a diversificar atividades em outros setores da economia (ou, no caso dos conta-próprias, a também se assalariar em outro estabelecimento), seja no comércio ou na indústria de transformação ou da construção, etc, tornando-se famílias pluriativas.

A interseção entre os dois conjuntos de ocupações (agrícolas e não agrícolas, ou agrícolas por conta-própria e agrícolas por assalariamento) não pode prescindir de nenhum deles, senão desfaz-se a interseção e, por conseguinte, a pluriatividade desaparece. Com base nessa compreensão lógica formal, considerase imprescindível associar a diminuição da pluriatividade na Região Sul à diminuição do número de produtores familiares da região. Dessa forma, os dados que aqui estamos expondo são essenciais para sustentar nossa hipótese de que a possibilidade de crescimento da pluriatividade na Região Sul acha-se comprometida.

Nesse sentido, a tendência de declínio (ou de não crescimento) da pluriatividade na Região Sul pode ser explicada essencialmente por duas razões: i) em parte, por razões opostas às que dizem respeito ao Nordeste - ou seja, não se deve ao atraso econômico, mas justamente ao fato de ter uma economia regional mais rica e moderna, com atividades econômicas dinâmicas mais espalhadas pelo seu território ${ }^{22}$ (o 'lado não agrícola'), que oferecem oportunidades de ocupação em atividades não agrícolas mais atrativas do que as agrícolas; e ii) em parte, não se deve ao predomínio de uma agricultura tradicional (caso do Nordeste), mas à combinação de uma agricultura moderna e predominante na região, que é competitiva e excludente, com o desamparo de um largo segmento de pequenos produtores familiares no que respeita a políticas de incentivo à agricultura familiar (o 'lado agrícola'). A conjugação desses dois pontos determina não a conformação de casos crescentes de pluriatividade, diferentemente do que a ideia prevalecente na literatura poderia esperar, mas fundamentalmente é a base para a configuração de casos crescentes de famílias rurais não agrícolas.

(22) Santos (1993) e IPEA/IBGE/NESUR (2001) fornecem os argumentos que mostram o dinamismo expressivamente maior das redes urbanas no interior da Região Sul, comparativamente à Região Nordeste. 
Os autores que estudaram a pluriatividade na Região Sul não associaram esse conjunto de determinantes às famílias rurais não agrícolas, e, por esta razão, entende-se que se equivocam fazendo a associação diretamente à pluriatividade. A hipótese original do Projeto Rurbano (IE/Unicamp), baseada na literatura européia, era de que a pluriatividade no Brasil estaria aumentando em decorrência do crescimento, registrado pelas PNADs, da PEA rural não agrícola. De imediato o Projeto Rurbano associou o crescimento da PEA rural não agrícola a um hipotético aumento da pluriatividade. Mas, quando, na Fase II desse Projeto, os pesquisadores foram estudar a pluriatividade constataram que, a despeito do crescimento da PEA rural não agrícola, a pluriatividade não crescia (Souza, 2000; Mattei, 1999). O Nordeste, por ser uma região pobre, de entornos rurais pobres, e pelo fato de a literatura negar a possibilidade de crescimento da pluriatividade em regiões com tais características, não lhe foi dada a devida importância até então. No Sul, onde se pensava estarem reunidas as qualidades para o crescimento da pluriatividade, esta achava-se em franco declínio. Qual foi a resposta dada pelos autores que estudaram esse caso (Sacco dos Anjos, 2003; Schneider, 2003; Schneider; Navarro, 2000)? Associaram-no ao 'lado não agrícola'. ${ }^{23}$ Associaramno ao processo de reestruturação produtiva ocorrida na Região Sul, nos anos 1990, em que essa região perdeu plantas industriais calçadistas e têxteis e que, por essa razão, a pluriatividade supostamente estaria sendo afetada negativamente. ${ }^{24}$ Entretanto, esses autores não deram a devida importância ao crescimento concomitante ao declínio da pluriatividade - do número de famílias rurais sulinas não agrícolas. Ou seja, por que as perdas das plantas industriais têxteis e calçadistas afetaram negativamente a pluriatividade e não afetaram da mesma maneira as famílias rurais não agrícolas, já que estas, ao contrário das pluriativas, aumentaram em número? Ora, o fator determinante, não reconhecido pelos referidos autores, que estavam muito influenciados pelo modelo europeu de entendimento da pluriatividade, é exatamente o fato de que muitas unidades rurais familiares agrícolas foram fechadas devido ao processo de ajuste estrutural ocorrido no período analisado pelos referidos autores, os anos 1990. Certamente

(23) Do ponto de vista do 'lado agrícola', Schneider (2003), por exemplo, somente enfatiza o declínio da PEA agrícola, e associação nenhuma é feita entre o declínio de unidades familiares agrícolas e o declínio da pluriatividade no Sul (aliás, para esse autor, existe uma tendência de crescimento da pluriatividade no Sul; mas isso ele extrai de uma pesquisa de campo feita por ele em um único ano).

(24) Sacco dos Anjos (2003) atribui, com muita propriedade, a queda da pluriatividade no Rio Grande do Sul, como sua segunda explicação, à profunda reestruturação sofrida pelo conjunto da agricultura familiar nos anos 1990. No presente trabalho, entretanto, queremos reforçar ainda a idéia de que a "crise" agrícola (que levou à reestruturação do setor) nos anos 1990 deve ser tratada como uma manifestação não de um momento conjuntural, mas de um elemento estrutural objetivado no próprio modelo agrícola moderno difundido na região. E que, portanto, esse é 'o' elemento que, na ausência de políticas compensatórias, impede a pluriatividade de crescer, levando-a até mesmo ao declínio. Significa dizer que, havendo ou não crise no setor, a lógica interna do modelo agrícola (elemento estrutural) permanece disciplinando o setor e ameaçando (de expulsão) os produtores ineficientes, entre eles, muitos pequenos produtores familiares pluriativos. 
grande parte dessas famílias que largaram a atividade agrícola - e, portanto, comprometeram a combinação 'agrícola com não agrícola' da pluriatividade tornaram-se famílias estritamente não agrícolas, ou até mesmo famílias de não ocupados.

Observe-se que os dados apresentados nas Tabelas 1 e 3 chamam atenção não apenas para a evolução do número de famílias rurais pluriativas ou agrícolas, mas também, e de modo especial, para a evolução do número de famílias rurais não agrícolas - ou seja, famílias rurais sem nenhum vínculo com a agricultura. É exatamente esse tipo de família que mais cresce nas áreas rurais sulinas. As Tabelas 1 e 3 mostram que, no Sul, diminui o número de famílias conta-próprias (agricultura familiar) agrícolas, não compensado pelas famílias conta-próprias pluriativas, porque o número dessas também declina, mas é compensado pelo crescimento do número de famílias rurais (conta-próprias e assalariados) não agrícolas.

As explicações, portanto, para a tendência ao declínio (ou não crescimento) da pluriatividade nessa região podem estar associadas ao efeito da contradição inerente ao padrão hegemônico ${ }^{25}$ de produção agrícola presente na Região Sul, cuja expressão mais importante - para os propósitos deste trabalho reside na redução do número de produtores familiares, na medida em que o setor agrícola como um todo é pressionado a se ajustar para elevar a eficiência do seu sistema produtivo. Esse processo ocorreu com mais força nos anos $1990 \mathrm{em}$ resposta à maior exposição à concorrência dos sistemas produtivos externos, provocada pela abertura da economia brasileira ao comércio internacional. Esse é o aspecto da "crise" 26 agrícola dos anos 1990 que nos importa aqui realçar: a exclusão de parcelas de produtores familiares que não lograram acompanhar a nova rodada de modernização do aparato produtivo agrícola exigida pelo ambiente mais hostil desse período.

É no processo de concorrência que se verifica a contradição entre o esforço frenético, de um lado, dos produtores agrícolas individuais por incorporarem inovações (produtos, processos, tecnologias) no interior de suas unidades produtivas (explorações agrícolas) e, de outro lado, a expulsão de parcelas de produtores individuais da participação na divisão do trabalho social (no que respeita ao âmbito do mercado), por não lograrem se ajustar às exigências da concorrência por aumento de eficiência produtiva (aumento de produtividade e redução de custos). Em outras palavras, quanto mais se acirra a concorrência entre

(25) Hegemônico porque é proporcionalmente mais difundido em todos os estratos de tamanhos dos estabelecimentos rurais sulinos mais do que se verifica em qualquer uma das outras regiões do país particularmente na Região Nordeste -, conforme mostrado em Nascimento (2005a; 2006).

(26) Crise entre aspas porque importa reconhecer que além dos perdedores (pequenos produtores familiares) houve também ganhadores (produtores ligados ao agronegócio), conforme Nascimento (2005a). 
os capitais individuais, tanto mais se acirra a necessidade de aprofundar o processo de modernização dos aparelhos produtivos, o que conduz a um processo inverso traduzido em redução do número de produtores aptos a permanecerem na corrida da modernização. Trata-se, portanto, de uma dinâmica sistematicamente seletiva a favor dos mais aptos, eficientes, capazes. Aos inaptos resta a exclusão do mercado. $^{27}$

A resultante final dessas forças tem sido, de um lado, o fortalecimento de uma base mais estreita de produtores altamente modernizados e, de outro, o alargamento da exclusão de parcelas de produtores que, a despeito do histórico descaso das políticas públicas destinadas ao meio rural, ainda se mantinham no âmbito da disputa por alguma fatia do mercado através de sua integração às cadeias do agronegócio, favorecidos, que eram, pela proteção contra a concorrência externa. Entende-se que esse lado de exclusão de parcelas crescentes de produtores incapacitados a se modernizar está estreitamente associado à tendência ao declínio da pluriatividade no Sul do Brasil.

Nesse sentido é que se entende que se torna imprescindível o apoio do Estado, consubstanciado em políticas públicas específicas, para conter o potencial processo de abandono das atividades agrícolas por parte de uma grande fração de produtores familiares incapacitados de se ajustarem às exigências da concorrência. Sem o apoio do Estado, como os pequenos produtores agrícolas familiares manterão suas atividades agrícolas $?^{28}$ E sem a atividade agrícola, como existirá (e aumentará) a pluriatividade? A pluriatividade não existe só com o elo não agrícola da combinação, que lhe é própria, 'agrícola com não agrícola'.

Sem esse apoio do Estado, e residindo em áreas rurais de redes urbanas dinâmicas, como as da Região Sul do Brasil, a tendência, a perspectiva, é conforme mostram as Tabelas apresentadas - de as famílias de pequenos produtores agrícolas se converterem não em famílias rurais pluriativas, mas em famílias rurais não agrícolas. Na União Européia, a perspectiva se dá mais no sentido da pluriatividade (razão pela qual o relatório final do Arkleton Trust Project, 1992, registra crescimento sustentável da pluriatividade na CEE, hoje $\mathrm{UE}$ ), justamente porque a PAC apóia os pequenos produtores rurais familiares a preservarem algum vínculo com qualquer atividade agrícola (não importando a natureza desta; se para o mercado ou não). Somam-se a esse apoio as características dinâmicas das economias locais (redes urbanas que circundam as

(27) As tabelas apresentadas anteriormente mostram a redução do número de famílias sulinas de contapróprias agrícolas e pluriativas (agricultura familiar) em estabelecimentos com menos de 100 hectares - para mais detalhes sobre esse ajuste estrutural, ocorrido nos anos 1990, ver Nascimento (2005a).

(28) No Nordeste as atividades agrícolas são mantidas como estratégia de sobrevivência porque lhes faltam, ao contrário do Sul, outras oportunidades, não agrícolas - nos entornos rurais, nas redes urbanas da região -, capazes de substituírem as atividades agrícolas, conforme explicado anteriormente. 
áreas rurais), e o resultado é mais pluriatividade. Sem esse apoio da PAC ao 'lado agrícola', tais características (o 'lado não agrícola') propiciariam a conversão das famílias agrícolas em famílias não agrícolas, mas não em pluriatividade (pelo menos não do ponto de vista de uma perspectiva de crescimento sustentável).

Não se quer negar que, sem o apoio público ao 'lado agrícola', o 'lado não agrícola' possa propiciar o surgimento de casos de pluriatividade. Isso é plenamente possível e casos semelhantes existem em todas as regiões do planeta. Os formuladores de políticas para as áreas rurais, interessados na pluriatividade, têm que se colocar a questão sobre o futuro da pluriatividade. Ela crescerá ou não crescerá para ajudar no esforço de combater a pobreza, o desemprego e o êxodo rural, conforme assim espera a literatura? A preocupação deste ensaio não é a explicação da existência de casos de pluriatividade no Sul do Brasil, mas quais são as suas perspectivas de crescimento

Nesse sentido, torna-se imperioso - na verdade, decisivo - o papel do Estado, das políticas públicas (de apoio ao 'lado agrícola'), porque o 'lado não agrícola' contribui para a existência de casos de pluriatividade, mas não assegura o crescimento do número de casos de pluriatividade, uma vez que a tendência histórica é de redução do número de produtores familiares agrícolas - tendência, essa, que pode ser acentuada ou atenuada dependendo do papel exercido pelas políticas públicas em relação ao 'lado agrícola'.

Dizer que o papel do Estado (apoiando o 'lado agrícola') é decisivo não significa dizer que o 'lado não agrícola' não seja importante. Significa, fundamentalmente, dizer que numa região como o Sul do Brasil, que tem o 'lado não agrícola' bem desenvolvido - pelo menos bem mais que o Nordeste brasileiro, segundo o IPEA/IBGE/NESUR (2001) - e que poderia, em tese, estimular a pluriatividade, se não houver estímulos também pelo 'lado agrícola', particularmente para os pequenos produtores historicamente alijados do apoio público, não haverá perspectivas de crescimento de casos de pluriatividade. Poderá, sim, haver mais perspectivas de crescimento de casos de famílias rurais não agrícolas. E o que pode estimular, apoiar, o 'lado agrícola' (de pequenos produtores) senão o Estado, as políticas públicas? As tabelas apresentadas mostram, conforme já mencionado, o crescimento das famílias rurais sulinas não agrícolas que dão sustentação a essa hipótese.

Argumentar sobre a importância da política pública não exclui a importância do 'lado não agrícola' apontado pela literatura para o caso da União Européia (e por autores brasileiros que também utilizam o 'lado não agrícola' para afirmar que o Sul do Brasil, ao contrário do que os dados da PNAD mostram, tem as condições para o desenvolvimento/crescimento da pluriatividade), supostamente determinante da pluriatividade. Pelo contrário, o argumento da 
política pública considera o 'lado não agrícola'. Apenas o considera insuficiente para explicar a evolução da pluriatividade, seja na UE, seja no Sul do Brasil. Dizer que é insuficiente não quer dizer que não seja importante, em absoluto. A questão é que os determinantes da pluriatividade, na referida literatura, ficam restritos ao 'lado não agrícola'. E a evolução da pluriatividade não se explica plenamente só pelo 'lado não agrícola'. Faz-se necessário pensar o 'lado agrícola' (da combinação 'agrícola com não agrícola', definidora da pluriatividade). Para pensar o 'lado agrícola', que diz respeito à permanência ou ao abandono das atividades agrícolas, especialmente por parte dos pequenos produtores familiares, importa considerar o papel do Estado, das políticas públicas.

Isso é o que a literatura especializada, importada da UE, não considerou. Por quê? Porque o problema inerente a essa literatura - e isso é o que induziu ao equívoco no Brasil - está em associar a ampliação da pluriatividade aos estímulos ao fomento de atividades não agrícolas para as populações rurais, ao fomento a ações voltadas para o desenvolvimento rural, ações que fortalecem, potencializam, todos os ativos histórico-culturais que eles possuem nas áreas rurais e ao redor delas. A importância da pluriatividade para a UE é que ela - no caso, associada ao estímulo à diversificação de atividades em outros setores da economia - teria a função de conter a queda histórica das rendas agrícolas, estabilizando as rendas das famílias rurais ligadas a alguma atividade agrícola, evitando basicamente dois processos indesejáveis: i) o empobrecimento dessas famílias; e ii) o êxodo rural.

A literatura da UE sobre a pluriatividade não considera o 'lado agrícola' com a conotação dada no presente trabalho - da pluriatividade justamente porque a PAC criou - esse é o verbo mais apropriado - uma situação relativamente estável, do ponto de vista da renda familiar, para inúmeros pequenos produtores familiares, de modo que a literatura européia (e aí a brasileira a segue) associa a pluriatividade fundamentalmente às ocupações rurais não agrícolas - ORNAs (o 'lado não agrícola'): i) entornos rurais (redes urbanas regionais/territoriais) com economias dinâmicas, ofertantes de ORNAs; ii) estratégias familiares de diversificação de atividades não agrícolas (ORNAs), não necessariamente de sobrevivência; iii) as migrações de parentes/familiares que se ocuparam em ORNAs, que viabilizarão remessas de rendas não agrícolas para os estabelecimentos; iv) as infra-estruturas das economias locais, os recursos naturais, culturais e humanos são também aspectos a serem levados em conta ao analisar o maior ou menor êxito da pluriatividade em um determinado território. (Reis; Hespanha; Pires et al., 1990; Marsden, 1990; Fuller, 1990; Brun; Fuller, 1991; Arkleton Trust, 1992; OECD, 1998). Os trabalhos desenvolvidos no Brasil não fogem desses determinantes (Kageyama, 1998; Mattei, 1999; Souza, 2000; Schneider, 2003; Sacco dos Anjos, 2003, entre outros). 
Carlos Alves do Nascimento

Perceba-se que a ênfase dessa literatura especializada recai no 'lado não agrícola' da combinação 'agrícola com não agrícola' (própria da pluriatividade), razão pela qual tal literatura procurou enfatizar a suposta relação entre economias locais/regionais dinâmicas do ponto de vista não agrícola (redes urbanas com economias e mercado de trabalho fortes, comércio, etc.) e a pluriatividade. A essa relação o presente artigo já se contrapôs com o caso do Nordeste brasileiro.

Mas, observe-se que, não obstante a ênfase recaia sobre o 'lado não agrícola' na UE, a associação feita não é com o que realmente dever-se-ia associar: as famílias rurais não agrícolas, mas com a pluriatividade supostamente para explicar o sucesso da pluriatividade na UE (e, no caso brasileiro, para explicar que o Sul tem todas as condições para o crescimento da pluriatividade).

Note-se que o 'lado agrícola' na concepção presente (e que é central) na referida literatura perde importância. Entendemos, todavia, que não somente o 'lado não agrícola' deve ser fomentado, mas também o 'lado agrícola' deve ser protegido, valorizado, evitando o abandono das atividades agrícolas pelos pequenos produtores. Porque o 'lado não agrícola', quanto mais dinâmico, e sem políticas que valorizem os pequenos produtores agrícolas, pode viabilizar o crescimento de famílias não agrícolas e não de famílias pluriativas. ${ }^{29} \mathrm{O}$ crescimento de famílias pluriativas só é possível se juntamente com os diversos estímulos ao 'lado não agrícola' (as redes urbanas que circundam as áreas rurais, etc.) houver também estímulos ao 'lado agrícola', especialmente aos pequenos produtores agrícolas familiares, que representam a fração mais numerosa do universo de unidades produtivas rurais agrícolas. E quem é o responsável por esses estímulos aos pequenos produtores agrícolas familiares na UE, senão a PAC? Sem a PAC, o artigo de Nascimento (2005b) mostra que numerosos pequenos produtores familiares da UE não existiriam e junto com eles não existiria o sucesso de casos de pluriatividade porque a PAC viabiliza a permanência dos agricultores "ineficientes" - do ponto de vista da sua produção para o mercado ligados a uma atividade agrícola (mesmo que seja para não produzirem nada para o mercado, mas somente para "preservar a natureza").

Nascimento (2005b) mostra que a PAC suscitou um comportamento por parte de muitos agricultores que revela uma certa dose de conveniência, por parte dos mesmos, em se manter algum tipo de atividade agrícola (mesmo que seja apenas para preservar a paisagem), o que lhes permitiria o acesso à política de subvenção ao setor. Juntando-se a isso, o esforço das políticas de desenvolvimento

(29) Com isso não se está querendo contrapor - em termos de juízo de valor - um tipo de família a outro, se um é melhor do que outro. Apenas se está argumentando, academicamente, sobre o que pode favorecer o crescimento de um e de outro tipo familiar. 
rural voltadas para ampliar a infra-estrutura e a oferta de ocupações não-agrícolas, o resultado final só pode ser o crescimento do número de famílias pluriativas.

Nascimento (2005b) fundamenta-se em vários autores europeus para mostrar que a PAC é decisiva para condicionar a manutenção do vínculo de numerosos pequenos produtores familiares a uma atividade agrícola na UE, e que, sem as subvenções da PAC, grande parte desses numerosos produtores abandonaria as atividades agrícolas - comprometendo a pluriatividade - e convertendo-se apenas em famílias não agrícolas.

Como já há toda uma fundamentação em Nascimento (2005b) para essa compreensão da importância do 'lado agrícola' para o crescimento de casos de pluriatividade na UE, considero que é suficiente apenas fazer referência ao autor, nesta comparação que no presente texto se faz com o Sul do Brasil, para que o leitor possa buscar tal fundamentação. Ambos os textos se complementam.

Por outro lado, a literatura associa também a pluriatividade à modernização da agricultura (ver, por exemplo, Carneiro, 1996; Schneider, 2003), uma vez que a modernização significa aumento de produtividade no interior das unidades produtivas familiares e, conseqüentemente, liberação de parte da família para se ocupar em outras atividades, fora da agricultura, resultando em conformação de casos de famílias modernas pluriativas. Contudo, essa literatura não considera os dois lados do movimento dialético presente nesse processo de modernização e de conformação de casos de pluriatividade. Um dos lados é o já descrito, da relação entre modernização, aumento de produtividade, liberação da força de trabalho familiar e pluriatividade. $\mathrm{O}$ outro, não mencionado por essa literatura, é o de que a modernização significa, para muitos pequenos produtores familiares, exclusão do mercado. Nesse caso, muitos deles ou permanecerão marginalizados na sua relação com a terra ou se tornarão famílias não agrícolas, porque tenderão a abandonar a atividade agrícola que lhes passa a ser mais onerosa do que o contrário.

Por ficarem marginalizados do processo de modernização (e de integração aos circuitos comerciais e produtivos dos agronegócios), haverá sempre a tendência a abandonarem a atividade agrícola, sobretudo tendo-se em vista alguns fatores que contribuem para essa decisão (forçada pelas circunstâncias). Quais sejam: a) a difusão, através dos meios de comunicação de massa, dos hábitos e necessidades urbanos; b) a crescente dificuldade de manter uma atividade agrícola não remuneradora; c) conjunturas duradouras de crise no setor agrícola; d) entornos rurais (economias locais) dinâmicos, do ponto de vista não agrícola, proporcionando maiores oportunidades ocupacionais fora da agricultura; e) o descaso histórico do Estado - consubstanciado em políticas públicas específicas no tocante ao amparo aos pequenos produtores. 
Do ponto de vista dos anos recentes, 2001 a 2005, a estabilidade (no sentido estatístico) da pluriatividade na Região Sul, registrada nas Tabelas 7 e 8 , pode ser entendida como um reflexo de todas as transformações ocorridas no setor. Refere-se às transformações sofridas pelo setor agrícola em função dos efeitos provocados pelas mudanças nas políticas macroeconômicas nos anos 1980 e 1990, que acirraram a modernização e a concorrência no setor agrícola, desencadeando um processo de aprofundamento da dinâmica interna, concentradora e excludente (ajuste estrutural), própria do modelo de agricultura moderna predominante na Região Sul, conforme mencionado.

Esse modelo de agricultura moderna comporta uma contradição - um movimento dialético - que lhe é imanente, como citado acima: por um lado, libera, em decorrência dos aumentos de produtividade, força de trabalho no interior de uma certa parcela das unidades familiares agrícolas para se ocupar em outros setores da economia, provocando, dessa forma, como resultante do processo, a proliferação de casos de famílias pluriativas. Mas, por outro turno, esse modelo agrícola não oferece, assim como ocorre em qualquer outro setor produtivo da economia capitalista, espaço, simultaneamente, para todos os produtores familiares. Isso significa que, em um determinado horizonte de tempo do desenvolvimento das forças produtivas no interior da agricultura, cada vez menos produtores familiares lograrão permanecer participando da dinâmica do hard core dos circuitos produtivos e de comercialização. Adicionando a essa redução do número de produtores familiares selecionados, o possível abandono das atividades agrícolas tradicionais por parte dos não selecionados reduz-se também o número de famílias pluriativas.

Esse processo, no entanto, não implica um automático e inexorável abandono do setor pelas famílias pluriativas e agrícolas "ineficientes", seguido de sua conversão em famílias não agrícolas ou de não ocupados. Essa é uma questão que dependerá do grau de dinamismo econômico dos entornos rurais (as economias locais ${ }^{30}$ ). Para os produtores familiares descapitalizados e incapacitados de competir por um espaço no mercado, se o entorno rural (as redes urbanas) que os envolve for dinâmico do ponto de vista não agrícola, pode-se supor, então, haver uma plausível tendência de parte dessas famílias se tornarem famílias não agrícolas (esta é a explicação que damos para o caso da Região Sul, notadamente nos anos 1990). No caso de as redes urbanas circunvizinhas às áreas rurais (economias locais) não serem dinâmicas o suficiente para oferecer oportunidades ocupacionais não agrícolas capazes de incentivar a substituição das atividades agrícolas precárias, arcaicas, nesse contexto, sim, essas famílias tenderão a se

(30) No caso do Nordeste, um entorno rural precarizado resulta em mais pluriatividade. No Sul, que comparativamente ao Nordeste, possui redes urbanas mais ricas, entendemos que o referido processo resulta em mais famílias não agrícolas, em contrapartida de menos famílias agrícolas e pluriativas. 
tornar cada vez mais pluriativas (julga-se ser esse o caso que explica o crescimento da pluriatividade no seio da pobreza da Região Nordeste) por uma questão de natural estratégia de sobrevivência.

Isso não significa que, de outro modo, nas conjunturas mais favoráveis ao setor - como é o caso do período $2001-2005^{31}$-, a mencionada contradição interna ao modelo agrícola deixe de existir. $\mathrm{Na}$ verdade, ela sempre estará presente, especialmente numa economia globalizada como a brasileira. O que ocorre é que uma conjuntura favorável atenua a força interna da contradição inerente a esse modelo de produção agrícola, de modo que uma parcela mais larga dos produtores familiares se beneficia do ambiente menos conflitivo.

Nesses termos, a explicação da relativa estabilidade da pluriatividade e do conjunto da agricultura familiar na Região Sul, no período 2001-2005, passa por esta análise. Três elementos conjugados entre si contribuem para essa estabilidade. Os três se complementam. O primeiro diz respeito à inflexão no regime cambial a partir de 1999, revertendo o impacto negativo que o regime anterior provocava sobre o desempenho da agricultura. O novo regime cambial passou a funcionar como uma proteção contra a concorrência (em comparação aos anos 1990) para um leque maior de produtores familiares, particularmente em relação aos produtores sulinos. O segundo elemento concerne ao efeito resultante do processo de ajustamento da estrutura produtiva agrícola, tornando-a mais eficiente à medida que selecionou os mais capazes a permanecerem na disputa no mercado (mais globalizado) - processo esse que se desenrolou ao longo das duas últimas décadas - de forma mais aprofundada na década de 1990. Entendemos que o efeito resultante levado a cabo pelo ajuste estrutural das unidades produtivas na Região Sul possui o significado de que o conjunto de produtores rurais que foram selecionados (que puderam se proteger) durante a crise dos anos 1990 iniciou a presente década com mais possibilidades de preservação da sua capacidade de reprodução social. Alia-se a essa condição estrutural a conjuntura macroeconômica mais favorável (o primeiro elemento), que não está exercendo pressão, pelo menos não na mesma intensidade exercida nos anos 1990, por novos ajustes na estrutura produtiva do setor, traduzindo-se em uma menor pressão à (tendência de) expulsão de mais agricultores do setor. Por último, e não menos importante, em absoluto, no período em questão houve um aumento do número de contratos e valores do Pronaf apropriados pela Região Sul (Faria, 2006), de modo que esse dado pode indicar a existência de um efeito "amortecedor" sobre a tendência de abandono por parte dos pequenos produtores familiares, potenciais beneficiários do Pronaf, das suas tradicionais atividades agrícolas - fato este que pode favorecer a pluriatividade (no Sul, inibindo - ou até mesmo tendendo a inverter, caso, por exemplo, o Pronaf continue ampliando seu alcance - a

(31) Comparativamente aos anos 1990. 
tendência ao declínio da pluriatividade, conforme foi largamente registrado nos anos 1990).

Por essa lógica de análise, consideramos plausível supor que, dada a permanência latente da referida contradição no interior do modelo agrícola disseminado na Região Sul do país (muito mais do que na Região Nordeste), a alteração das condições macroeconômicas (e a não ampliação do alcance de Programas como o PRONAF) poderá acirrar o movimento contraditório intrínseco à estrutura agrícola predominante na Região Sul, e, novamente, os microdados da Pesquisa Nacional por Amostra de Domicílio - PNAD virem a registrar a continuidade do processo de redução da base familiar (particularmente, das famílias pluriativas) de produção agrícola sulina.

\section{Considerações finais}

Chamou-se a atenção para o fato de que as constatações extraídas da análise dos dados sugerem que não é o dinamismo não agrícola de um determinado entorno rural (economia local/territorial) o determinante último para a configuração de um quadro de crescimento de casos de pluriatividade em uma região. Se essa relação fosse verdadeira, seriam de esperar trajetórias opostas às que foram descritas pelos dados na Seção 2, tanto para a Região Nordeste (economias locais muito precárias) como para a Região Sul (economias locais mais dinâmicas).

Em outras palavras, se por um lado o artigo concorda com a existência de uma certa relação entre o crescimento econômico de uma economia territorial e o surgimento de casos de pluriatividade nas suas vizinhanças rurais (conforme averiguaram Mattei, 1999 e Souza, 2000), por outro lado, todavia, queremos enfatizar que o crescimento econômico de um dado entorno rural, ampliando a oferta de ocupações rurais não agrícolas, não é condição suficiente, embora necessária, para assegurar uma trajetória de crescimento da pluriatividade em uma área rural.

A presença de ocupações rurais não agrícolas nos entornos rurais é necessária, mas não suficiente para o crescimento da pluriatividade. Para garantir a suficiência, faz-se necessária ainda, do ponto de vista deste artigo, a presença ativa do Estado, através de políticas que incentivem a permanência da população rural (que detém algum acesso a terra) com alguma atividade agrícola - isto é, evitando o abandono dessas atividades. Ou seja, não haverá pluriatividade se as atividades agrícolas não forem também valorizadas.

Conclui-se que, entre outras coisas, a dinâmica da pluriatividade em uma determinada região rural encontra-se muito diretamente relacionada à dinâmica da sua PEA agrícola, talvez mais do que à dinâmica das ORNAs presentes no seu 
entorno. Em um outro trabalho (Nascimento, 2005b), procuramos enfatizar a importância fundamental que teve a preservação de inúmeros pequenos estabelecimentos agrícolas (ineficientes à luz do mercado) na União Européia, através da sua Política Agrícola Comum, para a configuração de casos crescentes de pluriatividade (crescimento considerado sustentável pelo Arkleton Trust, 1992). No Brasil, como jamais houve uma política agrícola com esse conteúdo social abrangente, o declínio (ou o não crescimento) da pluriatividade em regiões modernizadas (Região Sul, com perfil socioeconômico mais próximo da UE que o do Nordeste brasileiro) torna-se evidente, especialmente em momentos de crise no setor agrícola.

Ademais, pode-se concluir que não basta a família agrícola se tornar pluriativa para deixar de ser pobre (caso da Região Nordeste); tem que se tornar pluriativa numa região não pobre. Porém, se na região não pobre (ou menos pobre) predomina uma agricultura moderna que exclui pequenos produtores rurais e se, na mesma região, existem redes urbanas com economias dinâmicas espalhadas pelo território regional, as famílias agrícolas (pobres ou não pobres) tenderão a se proletarizar, tornando-se não agrícolas em vez de pluriativas. Esse é o caso da Região Sul, que, na falta de políticas públicas compensatórias destinadas a evitar o abandono das atividades agrícolas "tradicionais" por parte dos pequenos produtores, está vendo esses pequenos produtores familiares se tornarem não famílias pluriativas, mas famílias não agrícolas ou de não ocupados. Esse também poderá vir a ser o resultado no Nordeste numa futura conjuntura de crescimento econômico e modernização das estruturas agrícolas e dos entornos rurais (economias locais) no interior dessa região, uma vez que a tendência apontada pelos dados - para a Região Sul, com tais características - não autoriza aguardar um maior crescimento da pluriatividade (e da agricultura familiar), mas o contrário.

Concorda-se plenamente com a análise de que os processos de industrialização difusa ocorridos no interior da Região Sul - anteriormente aos anos 1980 - convergiram, em combinação com as características da agricultura camponesa da região, para a proliferação de casos de famílias rurais pluriativas (Sacco dos Anjos, 1995; Schneider, 1999). Contudo, as informações fornecidas e as ponderações desenvolvidas no presente trabalho nos levam a crer que as próprias condições econômicas criadas pela industrialização difusa, no tocante às redes urbanas dessa região, juntamente com o efeito do aprofundamento das práticas capitalistas na agricultura dessa região, não mais conduzem as famílias rurais a se tornarem pluriativas, mas a se tornarem progressivamente famílias não agrícolas. Essa é a tendência (em termos de perspectivas) que se poderá esperar também para a Região Nordeste, caso esta venha a passar por um processo de "modernização conservadora" semelhante à que a Região Sul experimentou. 
Carlos Alves do Nascimento

Em suma, a relevância dessas considerações todas reside em que se os formuladores de políticas públicas para as áreas rurais considerarem importante elaborar políticas para fomentar de maneira sustentável mais casos de pluriatividade $^{32}$ a fim de esta servir de instrumento para combater o desemprego rural e urbano, para segurar a população rural em seu local de origem, para revitalizar as economias locais/territoriais e sua sociabilidade, não será apenas fomentando ocupações rurais não agrícolas (ORNAs) que aquele objetivo será alcançado. Se a sociedade quiser apostar em um crescimento da pluriatividade como uma das formas de enfrentamento do desemprego rural-urbano e de desafogo das cidades, tem-se que incentivar (por meio da ampliação, por exemplo, do alcance do Pronaf) a permanência da população com alguma atividade agrícola - evitando o paulatino abandono das atividades agrícolas "tradicionais" -, além de lhe proporcionar mais oportunidades ocupacionais não agrícolas. $\mathrm{O}$ apoio público à preservação do vínculo a uma atividade agrícola precede a sustentabilidade do crescimento da pluriatividade.

\section{Referências bibliográficas}

ALVES, M. O. Pluriatividade no sertão nordestino: uma estratégia de sobrevivência - o caso do município de Tejuçuoca, estado do Ceará. Revista Raízes, v. 21, n. 1, jan./jun. 2002 .

; VALENTE JR., A. S.; BRAINER, M. S. C. P. Pluriatividade no espaço rural do pólo Baixo Jaguaribe. Fortaleza, Ceará: BNB, 2006. (Série Documentos do ETENE, n. 11)

; ___ $\quad$ _ Pl Pluriatividade no rural do pólo de desenvolvimento agrícola baixo Jaguaribe (Nordeste, Brasil): problemas e potencialidades. In: CONGRESSO IBEROAMERICANO SOBRE DESARROLLO Y MÉDIO AMBIENTE CIDMAII, 2, Puebla, México, 24-28 out. 2005.

ARKLETON TRUST. Adaptation des menages agricoles en Europe Occidentale 19871991 - Rapport final du programme de recherche sur les structures et la pluriactivité des menages agricoles. Luxembourg: Commission Européenne, 1992.

CARNEIRO, M. J. Pluriatividade no campo: o caso francês. Revista Brasileira de Ciências Sociais, n. 32, ano 11, p. 89-104, out. 1996.

CARVALHO, F. F. Da esperança à crise - a experiência das políticas regionais no Nordeste. Dissertação (Mestrado)-Instituto de Economia, Universidade Estadual de Campinas, Unicamp, 2001.

FARIA, F. F. Distribuição de crédito para agricultura familiar: um estudo do Pronaf a partir de um indicador de desenvolvimento rural. Dissertação (Mestrado)-IE/UFU, Uberlândia, 2006.

(32) E, no caso do Nordeste, uma pluriatividade que combine proletarização com superação da pobreza. 
FIGUEIREDO, N. M. S.; HOFFMANN, R. A dinâmica da modernização da agricultura em 299 microrregiões homogêneas do Brasil: 1975, 1980 e 1985. In: CONGRESSO BRASILEIRO DE ECONOMIA E SOCIOLOGIA RURAL, 36, Poços de Caldas, MG, 1988. Anais... Poços de Caldas: Sober, 1998. p. 439-450.

FULLER, A. M. From part-time farming to pluriactivity: a decade of change in rural Europe. Journal of Rural Studies, n. 6, n. 4, p. 361-373, 1990.

GRAZIANO DA SILVA, J. O Novo Rural Brasileiro. Campinas, SP: UNICAMP-IE, 1999. (Coleção Pesquisas, 1).

HILL, B. F. The common agricultural policy: past, present and future. London: Methuen, 1984.

HOFFMANN, R. A dinâmica da modernização da agricultura em 157 microrregiões do Brasil. Revista de Economia e Sociologia Rural, Brasília, v. 30, n. 4, p. 271-290, 1992.

HOMEM DE MELO, F Os feitos negativos da política cambial sobre a agricultura brasileira. Economia Aplicada, São Paulo, n. esp., p. 35-46, mar. 1999.

. A década de 90 e o desempenho da agropecuária brasileira. Informações Fipe, n. 243, p. 20-23, 2001.

IPEA, IBGE, UNICAMP/IE/NESUR. Caracterização e tendências da rede urbana do Brasil: redes urbanas regionais: Norte, Nordeste e Centro-Oeste. Brasília: Ipea, 2001. v. 4, 263p. (Série de 6 volumes).

Caracterização e tendências da rede urbana do Brasil: redes urbanas regionais: Sul. Brasília: Ipea, 2001. v. 6, 206p. (Série de 6 volumes).

KAGEYAMA, A. Pluriatividade e ruralidade: aspectos metodológicos. Economia Aplicada, v. 2, n. 3, p. 515-551, jul./set. 1998.

MAIA GOMES, G. Velhas secas em novos sertões: continuidade e mudanças na economia do Semi-Árido e dos Cerrados nordestinos. Brasília: Ipea, 2001. 326p.

MATTEI, L. F. Pluriatividade e desenvolvimento rural no Estado de Santa Catarina. Tese (Doutoramento)-Instituto de Economia, Universidade Estadual de Campinas, Unicamp, 1999.

NASCIMENTO, C. A. A dialética da pluriatividade: o caso do Sul do Brasil. In: ENCONTRO NACIONAL DE ECONOMIA POLÍTICA, 11, Vitória, 2006. Anais... Vitória, ES: SEP, 2006.

Pluriatividade, pobreza rural e políticas públicas. Tese (Doutoramento)Instituto de Economia, Universidade Estadual de Campinas, Unicamp, 2005a.

A política agrícola comum da CEE e a ocupação das famílias rurais em atividades agrícolas e não agrícolas: lições para a política agrícola no Brasil. Economia e Sociedade, Campinas, v. 14, n. 2 (25), p. 263-286, jul./dez. 2005 b.

SACCO DOS ANJOS, F. Agricultura familiar, pluriatividade e desenvolvimento rural no Sul do Brasil. Pelotas: EGUFPEL, 2003. 374p.

SANTOS, M. A urbanização brasileira. São Paulo: Hucitec, 1993. 
Carlos Alves do Nascimento

SCHNEIDER, S. Agricultura familiar e industrialização: pluriatividade e descentralização industrial no Rio Grande do Sul. Porto Alegre: Editora da Universidade/UFRGS, 1999. $205 p$ 2003. 354p.

Pluriatividade na agricultura familiar. Porto Alegre: Editora da UFRGS,

; NAVARRO, Z. Emprego agrícola e novas formas de ocupação no Rio Grande do Sul: uma análise a partir dos dados das PNADs de 1981 a 1997. In: CAMPANHOLA, C.; GRAZIANO DA SILVA, J.(Org.). O Novo Rural Brasileiro: uma análise Nacional e regional. Jaguariúna, SP: Embrapa-Meio Ambiente/IE/Unicamp, 2000. v. 3. (4v.).

SOUSA, J. M. P.; VALENTE JR., A. S. Análise das liberações dos recursos do Pronaf descentralização das aplicações do crédito rural? In: CONGRESSO DA SOCIEDADE BRASILEIRA DE ECONOMIA E SOCIOLOGIA RURAL, 44, Fortaleza, CE, 2006. Anais... Fortaleza, CE: Sober, 2006. (CD-Rom).

SOUZA, M. Atividades não-agrícolas e desenvolvimento rural no Estado do Paraná. Tese (Doutoramento)- FEAGRI, Universidade Estadual de Campinas, Unicamp, Campinas, SP, 2000.

SOUZA, R. F.; KHAN, A. S. Modernização da agricultura e hierarquização dos municípios maranhenses. Revista de Economia e Sociologia Rural, Brasília, v. 39, n. 2, p. 81-104, abr./jun. 2001.

TOLOSANA, A. O.; PERSIVA, E. M. Estrategia de adaptación de pequeñas explotaciones en el marco de la PAC. La agricultura a tiempo parcial en una área de montaña. Revista de Estudios Agro-Sociales, n. 16, p. 99-122, jul./sept. 1992. 